\title{
Is routine physical examination of psychiatric in-patients really necessary?
}

\author{
Ian Porter
}

\begin{abstract}
Although there are some well recognised physical alleorders such as introcranial lesions that can present with mental iliness, many poychiativic conditions do not appear to be associated with undertying somatic complaints. However, a number of recent studies have shown that there are ofien high rates of concurrent medical conditions among acute psychiatric in-pationts that were previousty undiagnosed or unsuspected. The outhor illustrotes this point by presenting two case studies in which a sionificant medical condition was only identified afier physical examination on a poychiatitic unit.
\end{abstract}

A number of studies have looked at the rates of psychiatric morbidity among general hospital populations. In their review, Mayou \& Hawton (1986) noted that studies using sensitive screening methods had concluded that affective disorders of moderate severity were considerably more common in general hospital, than in the general population. They occurred more frequently in younger, socially deprived women and were often associated with evidence of longstanding psychological or social difficulties. Many studies have observed that hospital doctors and nurses underestimate and misdiagnose all forms of psychiatric disorder, but Mayou \& Hawton felt there was insufficient evidence to allow for an accurate assessment of the magnitude of this problem.

Other studies have specifically looked for physical conditions among those admitted to psychiatric units. Chandler \& Gerndt (1988) assessed 224 consecutive admissions to the University of Iowa Psychiatric Hospital. They looked at the role of the medical history and physical examination in changing the diagnosis and treatment of psychiatric syndromes and concurrent medical illnesses. A change in the psychiatric diagnosis or treatment occurred in $8.8 \%$ of cases as a result of these interventions. More significantly. $44 \%$ of admissions required treatment for a concurrent medical condition after assessment. The investigators found that the physical examination, with or without a confirming medical history, was the most im- portant predictor of the need for treatment of concurrent medical problems. Consequently, without a physical examination a number of significant medical illnesses would have been missed.

Walter-Ryan et al (1987) reviewed 564 consecutive psychiatric in-patient admissions in the United States to assess the frequency of associated medical illness. They found that almost $52 \%$ of this group had a significant medical disorder and that nearly half of these were new or previously unsuspected conditions. Concurrent medical disorders were more common in women, the elderly, substance abusers and those with non-schizophrenic functional psychoses. They highlighted the need for further research to define a profile of psychiatric patients at highest risk for medical illnesses.

\section{Case 1}

Mrs A was an elderly lady with a long history of recurrent episodes of agitated depression characterised by a rather 'histrionic' presentation with marked hypochondriacal features. Her symptoms had responded to previous hospital treatments such as electroconvulsive therapy or antidepressants. Five years ago her husband died and during her last hospital admission she expressed a wish to move into residential care since she felt isolated and lonely at home. Consequently, she had been discharged from hospital, on antidepressant medication, to a residential home of her choosing.

She had difficulty settling into her new home and despite her ability to wash and dress herself she repeatedly asked to move to a place where she could have more nursing care. She was taking her medication regularly but seemed to become increasingly anxious and restless. Suddenly, she appeared to develop a marked left-sided limp and had increasing difficulty bearing weight. The care staff had not witnessed a fall and she was rather vague about this when asked. After a few days she was unable to mobilise without the help of two 
staff members. Her general practitioner was called; he noted her 'odd gait' and her apparent lack of distress. He requested her admission to a psychiatric hospital with a diagnosis of conversion disorder. He felt that her 'secondary gain' was the wish for a potential transfer to a nursing home where she would be 'looked after'. He did not carry out a physical examination.

On admission she seemed mildly anxious but not overtly depressed. She was unable to weight bear without considerable support. Physical examination revealed physical signs and symptoms that were strongly suggestive of a fractured left neck of femur. She vaguely recalled a minor fall she had experienced a few days earlier. The fracture was confirmed on X-ray examination and she was successfully treated by the local orthopaedic department. She made a full recovery and she settled into the original residential home on her return there.

\section{Case 2}

Mr B was a middle-aged man with a number of previous psychiatric admissions for episodes of anxiety and depression, usually characterised by hyperventilation, shaking and restlessness. He had divorced eleven years ago and since then he had been living in supported lodgings run by an experienced landlord (an ex-psychiatric nurse) and other care staff. He took regular medication, valued his accommodation and had frequent contact with a community psychiatric nurse and the local industrial therapy workshop.

Over a number of weeks, Mr B had become increasingly anxious and agitated. His appetite decreased and his sleep pattern was disturbed. He was over-breathing and pacing the house. He expressed concerns about his physical health and about the future. He had told the care staff that he had some financial worries and they were concerned that he was becoming mentally ill.

His GP was called and prescribed thioridazine to see if he could reduce Mr B's agitation. Since there was no improvement after 24 hours, he requested an acute psychiatric admission for what he thought was an agitated depression. $\mathrm{Mr}$ $B$ had not received a physical examination during the year prior to admission.

In hospital, Mr B was restless and anxious but denied that he felt low in mood. He was unable to stop hyperventilating for more than a few moments at a time. Physical examination (with supplementary blood tests) revealed that he had chronic renal insufficiency with an associated pneumonia and a degree of left ventricular failure. After transfer to a medical ward he made a good recovery from his acute physical symptoms. When his mental state was reassessed his anxiety had settled and there was no evidence of a significant depresstve lllness.

\section{Discussion}

It is worth emphasising that all psychiatric patients should receive a physical examination on admission to hospital, the intensity of this examination depending on the patient's history and presenting symptoms. These two cases illustrate the importance of the physical examination in the assessment of acute admissions to a psychiatric unit. In each example, physical assessment played a vital role in helping to confirm, or refute, the psychiatric diagnosis as well as highlighting the presence of significant concurrent medical conditions.

In my experience, it is very unusual for local GPs to request a psychiatric admission without excluding physical pathology first. It is possible that the GPs and carers involved in these cases 'framed the symptoms' in mental illness terms, perhaps influenced by the past psychiatric histories. It is worth noting that both patients were rather 'vague historians' and this may have helped to obscure the physical aetiology of their symptoms. Consequently, significant physical pathology was missed in the absence of a physical examination prior to admission.

Mrs A had repeatedly expressed dissatisfaction with her accommodation and had requested to be 'looked after'. Subsequently, when she was suddenly unable to walk a 'conversion disorder' was suspected by her GP. There were certainly clues present to cast doubt on her psychiatric diagnosis. Scrutiny of her past psychiatric notes revealed that she had never presented with a conversion disorder before. Conversion symptoms occurring for the first time in someone of this age would strongly suggest an underlying physical aetiology. Although she initially failed to recall her recent fall, her 'unusual gait' and inability to weight bear were strongly suggestive of an underlying bone injury. A Royal College of Physicians Report (1989) noted that elderly people with hip fractures occupied about $20 \%$ of orthopaedic beds in England and Wales (in the 1980 s) and that approximately $80 \%$ of all hip fractures occurred in women over the age of 65 .

In view of Mr B's previous psychiatric presentations it is not surprising that others misinterpreted his symptoms by assuming he was 'relapsing' into a depressive illness. Consequently, his respiratory symptoms were attributed to his mental state rather than to a physical illness. An insidious condition, like chronic renal failure, may only present with non-specific symptoms such as lethargy and malaise. However, apparent respiratory distress, in a man unable to give a clear history, raised the 
possibility of significant underlying physical pathology.

\section{Conclusion}

These two cases emphasise the importance of physical examination in the assessment of psychiatric in-patients to aid in the diagnosis of both psychiatric and medical conditions. Although many psychiatric in-patients have no concurrent medical condition, recent research suggests that a high proportion may have previously undiagnosed or unsuspected physical pathology. Those assessing the patient are more likely to miss the presence of physical illness if the individual is acutely disturbed or unable to give a clear history of recent events. In these circumstances, a physical examination is even more vital if organic pathology is to be excluded. Improved education and liaison between psychiatrists and GPs could help avoid inappropriate admissions and reduce the risk of overlooking significant psychiatric or physical pathology.

\section{References}

Chanduer, J. D. \& Gerndt, J. E. (1988) The role of the medical evaluation in psychiatric inpatients. Psychosomatics, 29, 410-416.

MAYou, R. \& HAwron. K. (1986) Psychiatric disorder in the general hospital. Brttish Journal of Psychiatry, 149, 172 190.

THE RoYal Coluege of PHysicins of London (1989) Fractured Neck of Femur. Prevention and Management (Report). London: RCP.

WALTER-RYAN, W. G., ALARCon, R. D. \& MEADOWS, D. T. (1987) Toward a proflle of medically ill psychiatric patients. Southern Medical Joumal, 80, 822-826.

I. J. Porter, Senior Registrar in General Psychiatry, Fromeside Clinic, Blackberry Hill Hospital, Stapleton, Bristol BS16 1ED

Correspondence: Dr I. Porter, 36 Downend Park, Horfield, Bristol BS7 9PU

\title{
Gaskell Academic Series
}

\section{Interpersonal Factors in Origin and Course of Affective Disorders}

\author{
Edited by $\mathrm{Ch}$. Mundt, with the assistance of Hugh Freeman
}

This detailed overview of the latest research on affective disorders brings together authors of international background and repute. Both a theoretical and practical approach to the origin and course of affective disorders is presented, covering specific problems and settings. The principal areas covered are: personality factors, risk and course; social support; marital and family interaction; and intervention.

- £25.00 • 396pp. • Hardback • 1995 • ISBN 1902241907

Available from bookshops and from the Publications

Department, Royal College of Psychiatrists, 17 Belgrave Square,

London SW1X 8PG (Tel. 0171-235 2351, extension 146)

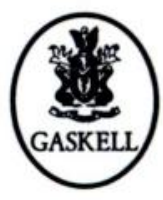

